Journal of the Scholarship of Teaching and Learning, Vol. 21, No. 4, December 2021, pp. 48-55. doi: 10.14434/josotl.v21i4.33011

\title{
Unresolved: Public Speaking Instruction Beyond Persuasion
}

\author{
Jonathan J. Edwards \\ University of South Carolina
}

\begin{abstract}
This essay advocates the use of "unresolved" speech assignments in introductory public speaking instruction. Unresolved speeches work to decenter persuasion in the speech class by asking students to critically explore the landscape of arguments surrounding controversial topics and issue questions without making the turn to opinion giving and persuasion.
\end{abstract}

Keywords: argument, critical thinking, fake news, opinion, rhetoric.

At least as far back as Aristotle's famous definition, Western rhetorical instruction has been linked with "the available means of persuasion" (Aristotle, 1991, I.11355b 1). Even though scholars across generations have challenged this persuasive fixation in rhetorical scholarship (see Bone et al., 2008, pp. 434-435), it remains firmly embedded at the level of the introductory public speaking class. In introductory speech textbooks and classes, much of our instruction continues to be bound up in Aristotelian categories and focused on describing effective communication in terms of generalizable and universal rules for effectively imposing a communicator's will on an audience. Yet, even in Aristotle's time this approach, as Paul Ricoeur argues, was already a reduction of the "dangerous power" of "undisciplined common speech" against which and through which rhetoric formed. Aristotelian rhetoric emerged as a "domesticated discipline, solidly bound to philosophy by the theory of argumentation" (Ricoeur, 1977, p. 10). Persuasion in some form has long been a part of public speaking, but it is neither the apex nor the whole of the art.

We should reconsider our Aristotelian focus on persuasion in the introductory public speaking class. As educators, we struggle to support and promote democratic values in our classrooms while wrestling with the new and continuing challenges of political hyper-polarization, propagandistic media, conspiratorial narratives, and the unambiguous championing of deceptive, divisive, and rule-violating speech. Our students need to be critical thinkers and effective researchers. They need to understand and appreciate the varieties of embodied performance and the disproportionate risks of democratic engagement for different populations. They need to understand how polarization and propaganda and demagoguery work and whose voices are excluded from public debates. They need to become effective speakers who know how to use their unique voices and bodies as well as their words. This is hard work. It is slow, sometimes painstaking, sometimes exhilarating work. And in the tight timeframe of an introductory class, very little of this work is aided by the insistence that students also attempt to orient their speeches around persuading their classmates.

In this article, I propose that we decenter persuasion in the introductory speech class by promoting the use of "unresolved" speaking assignments that ask students to critically explore the landscape of arguments surrounding controversial topics and issue questions without making the turn to opinion giving and persuasion. Unresolved speeches are one means by which we can help our students explore the variety of available arguments, narratives, and embodied engagements related to an issue while also learning to organize research, evaluate resources, and speak effectively to an audience. Unresolved speeches encourage students to critically investigate perspectives, communities, systems, styles, and other factors of a controversy at greater depth and with more nuance than they could achieve in an assignment that short-circuits this process by demanding that they leap from exploration to opinion and then persuasion. In what follows, I briefly outline and contextualize the 
approach before turning to consider ways in which an unresolved speaking assignment might be incorporated into the classroom.

\section{The Persuasion Fixation}

The Aristotelian association of rhetoric and persuasion has been challenged in various ways and particularly over the past century. The work of Kenneth Burke pushed rhetorical scholarship toward a conception of rhetoric that privileges "identification" and "consubstantiality" between the speaker and the audience over an Aristotelian conception of persuasion (Burke, 1969, pp. 20-23). Robert Scott (1967) helped usher in an expansive scholarly conversation on rhetoric as "epistemic" or knowledge generating. Scholarship in invitational rhetoric has attempted to push rhetorical thinking away from the potential violence of persuasive approaches and toward a model the privileges mutuality, cooperation, and openness as means for more effective communication (Bone et al., 2008; Foss \& Griffin, 1995). A growing body of scholarship is challenging the White, Eurocentric, and patriarchal biases in rhetorical education models that insistently place Greece and Rome at the historical center (see Bell \& Jackson, 2021, p. 1). Yet when introductory speech instructors address students every semester, we return again and again to persuasion as the model. Not only are Aristotelian concepts such as ethos, pathos, and logos prominently featured in most major public speaking courses and textbooks, but the structure of the speech class itself is set up to prioritize persuasive speaking that attempts to win over an audience to the speaker's way of thinking.

In a political and media climate consumed with "fake news" and concerns about the corrosive effects of what J. Hillis Miller (2017, p. 305) called the "word magic" of politicians whose speech changes both believers and opponents, many instructors are struggling to figure out how to help students critically navigate and effectively engage with the befuddling array of ideas and opinions they encounter. One long-standing reaction to the growth of opinion culture online is the idea that better training in argument will impart rigor and teach students to recognize the difference between objectively good and bad arguments. A classic version of this reaction is to say that students should be taught that they are only entitled to the opinions that they can successfully defend through rigorous argument (see Stokes, 2012). Certainly, it is valuable to teach students that not every opinion is equally credible and that pronouncing something "my opinion" should not be used to shut down conversation. Swapping out argument for opinion, however, does not sufficiently resolve the problems surrounding opinion or opinion culture.

The ability to shut down conversation by declaring your opinion on a given subject is a particularly rare and privileged position. In digital space, it is easier to declare one's opinion and walk away without facing significant consequences, although those with existing audiences and platforms have a much greater chance that their opinions will affect discourse and debate (Phillips \& Milner, 2017 , p. 168). In nondigital contexts, opinion sharing is often more difficult and carries more risk. It is harder still when there are unequal power dynamics involved. My students cannot simply tell me what they think of me and then leave my class midsemester without consequence because they are dependent on my evaluations of their work to secure a grade. A person pulled over by a police officer does not have the option to shout out their opinion at the officer and drive away, and even the limited options for opinion sharing that might be available in such contexts to White, cisgender men and women are barred for many individuals who are Black, Indigenous, or people of color and others who may fear that stating any "opinion" to a law enforcement official could have severe and even fatal consequences. The power to express an opinion is real power. In and beyond our classes, we must remain attentive to the inequitable distribution of "voice" and "how those from the margins craft their discursive spaces under the weight of immense institutional constraints" (Asante, 2019, pp. 486-487). The problem in many communication classes is not that all students are constantly shouting out poorly

Journal of the Scholarship of Teaching and Learning, Vol. 21, No. 4, December 2021. josotl.indiana.edu 
reasoned opinions; it is that a few—often privileged — students are too quick to offer up their opinions on every imaginable subject while others are reluctant to offer any opinions at all.

The solution is not simply to teach all our students more effective persuasion strategies. That is because easy-opinion-giving has never been simply a problem of argument. It is a problem intimately intertwined with access, status, and power. Communication pedagogy remains inadequately attentive to the inequities of opinion giving in part because, as Helene Shugart argued, much of the scholarship upon which that pedagogy is built remains "limited to the rhetorical strategies, and their effectiveness, of people (almost always White men, in fact) in positions of power" (2003, p. 276). Our classes and textbooks offer examples of people in positions of power giving responsible, civil, and well-reasoned speeches, but students can find many other examples of public and powerful figures who increase their power, success, and privilege using nothing more than their unresearched, unexamined, and even openly untruthful opinions (see Mercieca, 2020, p. 10). Such people rarely present reasoned arguments or offer meaningful evidence because they do not have to. Their success or failure does not depend on the quality of their argument; it depends on the strength of their popularity, their coalition, and their power.

This is not to say that teaching argument and persuasion is bad, but more effective argument instruction is not a magical salve that will heal our democratic governance or restore engaged citizenship or make any aspect of our public and civic life better. Argument is a tool for helping us present our opinions in more depth, but it does not in and of itself transform opinionated students into critical thinkers. If presented as a cure-all or the goal of rhetorical instruction, persuasion will magnify the problems it seeks to resolve. Students already inclined to share their opinions will use persuasion to find better justifications for those opinions, rather than challenging themselves and engaging meaningfully with the opinions of others. Meanwhile, the power dynamics that separate those who feel free to state their opinions and those who feel constrained against having or expressing opinions will continue to go unchallenged. Persuasion cannot disrupt the power systems that support opinion culture because it is part of those systems. Focusing on persuasion presupposes that everyone is coming at argument with an equivalent degree of power and influence, and everyone comes at and presents arguments in more of less the same way. Neither of these are true. The problem of fake news lies deeper than an absence of effective persuasion instruction; it lies in persuasion itself. Aristotelian persuasion-and all of the instructional and theoretical works that have derived from it-are ultimately dependent on Aristotle's assumption that truth will naturally defeat error in contexts where they are equally matched (Aristotle, 1991, I.1.1355a 12). That is the justification for teaching rhetoric as persuasion. If the right kind of persuasive speakers can be trained, they will be equally matched against frauds and tricksters, and truth and justice will win out in the end. Such an idea is at best incomplete and inadequate.

A persuasion perspective forces students to pick a side and defend that side. Every semester, students come to me and say that they are having a hard time taking a side or stating an opinion. I work with those students to help them develop persuasive speeches, and those speeches often do help the students develop new confidence. The more I teach, however, the less convinced I am that it is the persuasion that creates the confidence. Some students come into my classes full of opinions. They want to persuade everyone around them and advocate for their ideas. These students are excited to take a class where they can tell their classmates exactly what they should think and how they should act. They are excited at the prospect of making arguments, and they certainly benefit from learning skills that help them make their cases more strikingly, cite their sources better, and engage more effectively with an audience. It is not the case, however, that practice in argument is necessary for or even beneficial to their developing a deeper understanding of their subject or a deeper pool of resources. The fact is that almost all our students have more than adequate venues to practice making arguments. They can go on any social media platform — using their names or writing anonymously-

Journal of the Scholarship of Teaching and Learning, Vol. 21, No. 4, December 2021. josotl.indiana.edu 
and construct an argument about their chosen topic. They can make a web video. They can talk with friends or family members. Opinions are cheap, and that is one of the reasons why instructors and scholars tend to push back against the explosion of opinion culture. But where many of these instructors argue that we should be teaching better persuasion skills, I am inclined toward an approach advocated by educators such as John Dewey and Kenneth Burke that shifts our instructional focus from teaching "reflection" as a means to achieving persuasive "action" to "a pedagogy of reflection as action" (Enoch, 2004, p. 290).

In the time constraints of an introductory class, persuasive speeches do not teach students to consider fully the landscape surrounding an argument; they do not teach students to fully investigate the power dynamics at play in determining who gets to make arguments and why. Persuasion does not teach students to contemplate the boundaries of argument. It does not provide a good framework for asking students to think about why some arguments are worth making and worth having while others are not. Is it beneficial to argue with a religious extremist or a climate change denier or a flat earther or a white nationalist? If so, why and what are the limits of those arguments? If not, why not? These questions are not incidental. Many students are confronted daily with arguments that might previously have been regarded as fringe or that might not have been widely available. Persuasion and argumentation might teach students how to find the best research to combat "flat earth" arguments and how to organize those arguments in a structurally coherent way, but they will not answer the more fundamental questions about whether argument is the best approach when confronted by a flat earth conspiracist. After all, if students begin arguing with a flat earther, they might quickly realize that their interlocutor is not playing fair. The flat earth arguments boil down to a disjointed arrangement of ad ignorantiam challenges and redefined terminology that leave very little room for the kind of critical, reasoned thinking that we teach students to value in our classes.

Imagine instead that in our introductory classes we focused not on the development of more effective persuasion but on the critical exploration and analysis of arguments and perspectives and language use. When confronted with extremist views or seemingly irrational arguments, students would be better equipped to step back from the compulsive drive to argue back and instead consider what is really going on beneath the surface (see Enoch, 2004, p. 284). Is a flat-earth argument really about the earth's shape? Is this an argument about astronomy or physics? Or is this about deeper issues of trust in institutions, the power of community identity, the consequences of media insularity, and the appeal of narratives? In such cases, no argument-no assembly of proofs in the Aristotelian sense - is likely to have any persuasive effect because the reasons and evidence are not the point. The reasons are justification for an intuitive sense that there must be systemic conspiracies afoot beyond one's community and that people are lying and manipulating at all levels within academic, commercial, educational, and governmental agencies. It is this sense that something must be wrong that drives the reason giving, not the strength of the case for the earth being flat rather than a globe. By helping students step back and explore arguments without immediately trying to resolve them, we help them gain a better sense of the landscape surrounding the positions that people take and the communities they inhabit. This is a more effective path to critical thinking.

Before turning to the exercise, it is important to discuss an obvious objection. Public argument seems to be inundated with troubling appeals to the equivalency of "both sides" in debates and confrontations. In responding to violent and even deadly clashes involving White supremacist and neo-Nazi groups, prominent public figures have asserted that "both sides" include good people. In U.S. education, we have witnessed decades of legislation mandating that both biological evolution and a particular version of Christian creationism should be taught in public school science classes and given "equal time." In policy debates, we have seen repeated demands for equal attention to the environmental arguments accepted by the vast majority of climate scientists and the work of a small number of scientists and nonexpert commentators related to the issues of climate change. On issue

Journal of the Scholarship of Teaching and Learning, Vol. 21, No. 4, December 2021. josotl.indiana.edu 
after issue, positions that are functionally accepted as settled are highjacked and coopted by fringe advocates who play off basic narratives of fairness and equal representation to force people to listen to and, in many cases, financially support and implement their views (Allsop, 2019). Given this context and the growing concern that educators have for dealing with fringe theories and disinformation in the classroom, how can it possibly be a good idea to suggest eliminating or minimizing persuasion instruction in our introductory classes (see Greene \& Hicks, 2005, pp. 101-102; McMurtrie, 2021)? At a time when bad arguments are everywhere, how can it be a good idea to encourage students to argue less and consider context more? After all, is not "context" just another word for "both-sideism"? Are we not simply playing into the narratives of fringe communities and hate groups when we suggest that students spend more time considering multiple perspectives with regard to policy issues and spend relatively less time making and defending their own positions?

This critique is serious, and its implications have considerable significance both for our current concerns about the struggles for and over democracy in the United States and our long-term investment as educators in helping support a better, more diverse, and more engaged citizenry for the future. I do not want to deny or in any way minimize the damage that both-sideism has produced in the past and is continuing to generate in our current moment. Like many other communication instructors, I am deeply concerned about my role in helping students gain perspective and find their way through landmines of disinformation and open expressions of racism, misogyny, and violence. Indeed, it is precisely because of these concerns that I began seriously to reconsider the role and prominence of persuasion in my own introductory classes, because it seems clear that more instruction focused on rhetoric as argument and opinion giving is not a sufficient solution and may even be doing more harm than good. Treating every rhetorical exchange as a setup for persuasion often winds up strengthening the warped perspective that there are two equally valid sides to every imaginable issue and that the purpose of rhetorical reflection is to compete with and defeat the other side (Enoch, 2004, p. 273). As Leah Ceccarelli contended, when it comes to extremist or marginal arguments, the act of engaging in debate often risks lending legitimacy to fringe perspectives and communities (2011, p. 203). In a similar vein, Whitney Phillips and Ryan Milner argued that the act of engaging in online social media debates often produces the effect of magnifying and replicating offensive and abusive content: "Blanket assertions that more speech is the best response to bad speech often overlook differential power relations, and falsely presume that being heard is merely a function of speaking up and adding your voice to the clash" (2017, p. 184). Arguing is not neutral behavior. Arguing is contextual, and it affects the valuation of the sides being debated.

\section{Assignment: The Unresolved Speech}

In the remainder of this essay, I briefly explore one possible exercise to help decenter persuasion and focus on critical engagement with argument in the public speaking class. My purpose is not to eliminate persuasion altogether but to frame persuasion as one aspect of public speaking rather than its end or goal. I am calling the assignment the "unresolved speech." This assignment draws from ancient Greek progymnasmata exercises and the study of dissoi-logoi. It involves asking students to explore two to three substantive arguments, perspectives, or narratives on either side of a yes-or-no issue question. This kind of review is often used as a setup for a persuasive speech, but for the purposes of this speech assignment, I ask students not to resolve the question for the audience. Instead, students are given two goals. The first goal is to convince the audience that the question they are asking is significant. In our lives, we necessarily pick and choose among different issues that vie for our time and attention. We cannot care about everything equally. The student in this assignment is tasked with convincing the audience that this particular question is worth spending time and attention trying to resolve. The second goal is to convince the audience that the question is difficult to answer. If audience members

Journal of the Scholarship of Teaching and Learning, Vol. 21, No. 4, December 2021. josotl.indiana.edu 
came to the speech believing that the question had an easy or obvious solution-that one side was clearly right and the other side clearly wrong-it is the speaker's job to challenge the audience to reexamine those assumptions.

The challenge of this speech is to avoid answering or resolving the question and instead to leave the audience in suspense at the end. Of course, this does not mean that the speaker must feel neutral on the issue question. In fact, if they are neutral, the speech tends not to go well because the speaker will have a harder time convincing the audience that the question is worth trying to answer. Neutrality often implies that the stakes of making a decision are not very high, and therefore it does not really matter what perspective the speaker or audience holds. In contrast, if the speaker presents on an issue where they hold strong opinions, their challenge is to present both sides fairly and evenly without selecting a side by the end of the speech. This is qualitatively different from offering up counterarguments in the context of a persuasive speech. The point of a counterargument is to support or enhance the speaker's own position or perspective. Students set up counterarguments to knock them down, and no matter how much we attempt to help students think seriously about their counterarguments, a student delivering a persuasive speech in an introductory class will automatically begin filtering information to support their own perspective while minimizing or marginalizing data or arguments that challenge their perspective (see Keith, 2011, p. 83). The unresolved speech, in contrast, forces students to think about competing arguments and perspectives without immediately thinking about how to relate them back to their own persuasive goals. In other words, the point of the speech is to encourage the student to sit with and explore the landscape of possibility with regard to a policy issue or question. The more deeply the student investigates the range of possibilities, the more likely they are to find innovative solutions and to think beyond their individual biases and victories (see Enoch, 2004, p. 281).

This speech can stand on its own as a way of helping students learn critical thinking skills, or it can serve as a framework for a broader exploration of the perspectives and approaches surrounding a topic. As students study a question, they will often find that there are multiple perspectives and communities at play. They will learn that the definitions of words are often important and that these definitions may vary in significant ways from one interested community to another. Questions may lead to other questions, and students may discover that what seemed like a clear-cut debate between two opposing sides is closer to a mosaic of different interests that are aligned in some ways and not aligned in others. They may find that different voices have more or less power to speak or act and affect change with regard to the issue. They may find that some arguments are distractions or obfuscations. Through this process, students are learning to develop their skills as researchers and critical thinkers. In a class context, instructors could ask students to develop a series of unresolved speeches with each building off questions uncovered in the previous speech. Alternatively, this could be used as a single speech assignment that prepares students for a persuasive or advocacy speech. In the past, when using this assignment as preparation for a persuasive speech, I found that the overall quality of the persuasive speeches went up significantly. Students consistently demonstrated a deeper understanding of their topics, and they were better prepared to anticipate the questions and possible objections of their audience.

Finally, this assignment helps students build their confidence as speakers. As I mentioned above, some students are not comfortable expressing their opinions or trying to persuade others. Sometimes this discomfort derives from a student's personality or lack of experience; in other instances, it reflects real concerns about personal or social risks, power imbalances, cultural expectations, and so forth. We ask a lot of our students in introductory public speaking classes, and we should not discount the risks and challenges of asking them to stand up in front of strangers and give a speech while also revealing personal details about their experiences, beliefs, and opinions. The unresolved speech, in contrast, allows students to focus on research and presentation skills without

Journal of the Scholarship of Teaching and Learning, Vol. 21, No. 4, December 2021. josotl.indiana.edu 
the added burden of personal revelation. Through this assignment, students can explore their interests without being forced to choose a side or too quickly jump to opinion giving. Depending on how the assignment is set up, they can investigate not only the arguments surrounding an issue, but also the stylistic and delivery choices that advocates make when presenting their perspectives. Through this process, students can begin to develop their own speaking style and build their comfort and confidence in front of an audience.

\section{Conclusion}

The introductory speech instructor is perpetually fighting against the clock. Between formal graded speeches, impromptu assignments, question-and-answer sessions, and group projects, each student in a class may speak for 20,30, or even 40 min over the course of a semester. This time is critical to student learning and fundamental to skill development, but it means that other instruction can only take place in special sessions or around the margins of student presentations. Because most colleges and universities only require students to take, at most, one public speaking class, instructors are always making choices about what details are of vital importance to students and what details must be left out. In his analysis of public speaking syllabi, Pat Gehrke found that "the average public speaking class spends $7 \%$ of its time teaching public speaking, $53 \%$ of its time teaching speech writing, and $40 \%$ of its time for students to give presentations" (2016, p. 247). Furthermore, much of that speech writing instruction is dedicated to teaching students how to gather and organize evidence in service of their own arguments. The result, given the practical constraints of an introductory public speaking class, is often a preponderance of poorly developed arguments in which students select a few reasons to support their claim and then selectively pick out sources of evidence to support each reason along with a passing reference to one or two counterarguments if the instructor requires them. All of this information must be squeezed into a speech that may only be 6 or $7 \mathrm{~min}$ in length-and even less in some classes. This is not a recipe for effective persuasion or effective speech instruction. Students delivering these speeches are learning to seek simplicity over complexity. They are learning to cut corners and distort information in the service of a clearer speech and better grade. They are learning to value universal structures of argument over the nuances of contextual engagement with particular audiences. They are learning to fake sincerity and value self-assured declarations over curiosity and exploration. By offering students a necessarily truncated approach to persuasion, public speaking classes often not only teach bad argument but also create unrealistic expectations among students about what an effective argument looks like beyond the classroom.

By decentering persuasion in the introductory public speaking class-even for an assignment - we can give students a better foundation for success as both speakers and advocates. An assignment such as the unresolved speech helps students become better researchers, speakers, and critical thinkers. It offers students an opportunity to develop their skills while gaining a deeper appreciation for the nuances of real-world advocacy and the complexity of rhetoric as, and beyond, persuasion.

\section{References}

Allsop, J. (2019, December 16). Both sides. Columbia Journalism Review. https://www.cjr.org/the media today/both-sides-impeachment-trump.php Aristotle. (1991). On rhetoric: A theory of civic discourse (G. A. Kennedy, Trans.). Oxford University Press. 
Asante, G. A. (2019) \#RhetoricSoWhite and US centered: Reflections on challenges and opportunities. Quarterly Journal of Speech, 105(4), 484-488. https://doi.org/10.1080/00335630.2019.1669892

Bell, T. J. \& Jackson, R. L. (2021). Time for a change in how we teach public speaking across the world: Using culturally relevant pedagogy to teach public speaking in Chinese classrooms. Communication Teacher, 35(4), 304-312. https://doi.org/10.1080/17404622.2021.1892788

Bone, J. E., Griffin, C. L., \& Scholz, T. M. L. (2008). Beyond traditional conceptualizations of rhetoric: Invitational rhetoric and a move toward civility. Western Journal of Communication, 72(4), 434-462. https://doi.org/10.1080/10570310802446098

Burke, K. (1969). A rhetoric of motives. University of California Press.

Ceccarelli, L. (2011). Manufactured scientific controversy: Science, rhetoric, and public debate. Rhetoric \& Public Affairs, 14(2), 195-228. https://doi.org/10.1353/rap.2010.0222

Enoch, J. (2004). Becoming symbol-wise: Kenneth Burke's pedagogy of critical reflection. College Composition and Communication, 56(2), 272-296. https://doi.org/10.2307/4140650

Foss, S. K., \& Griffin, C. L. (1995). Beyond persuasion: A proposal for an invitational rhetoric. Communication Monographs, 62(1), 2-18. https://doi.org/10.1080/03637759509376345

Gehrke, P. J. (2016). Epilogue: A manifesto for teaching public speaking. Review of Communication, 16(2-3), 246-264. https://doi.org/10.1080/15358593.2016.1193943

Greene, R. W., \& Hicks, D. (2005). Lost convictions: Debating both sides and the ethical selffashioning of liberal citizens. Cultural Studies, 19(1), 100-126. https://doi.org/10.1080/09502380500040928

Keith, W. M. (2011). We are the speech teachers. Review of Communication, 11(2), 83-92. https://doi.org/10.1080/15358593.2010.547589

McMurtrie, B. (2021, January 12). Teaching in the age of disinformation. The Chronicle of Higher Education. https://www.chronicle.com/article/teaching-in-the-age-of-disinformation

Mercieca, J. (2020). Demagogue for president: The rhetorical genius of Donald Trump. Texas A\&M University Press.

Miller, J. H. (2017). Who speaks a lie? Qui Parle: Critical Humanities and Social Sciences, 26(2), 303-305. https://www.muse.jhu.edu/article/ 689588

Phillips, W., \& Milner, R. M. (2017). The ambivalent internet: Mischief, oddity, and antagonism online. Polity.

Ricoeur, P. (1977). The rule of metaphor: Multi-disciplinary studies of the creation of meaning in language ( $\mathrm{R}$. Czerny, Trans.). University of Toronto Press.

Scott, R. L. (1967). On viewing rhetoric as epistemic. Central States Speech Journal, 18(1), 9-17. https://doi.org/10.1080/10510976709362856

Shugart, H. A. (2003). An appropriating aesthetic: Reproducing power in the discourse of critical scholarship. Communication Theory, 13(3), 275-303. https:// doiorg.pallas2.tcl.sc.edu/10.1111/j.1468-2885.2003.tb00293.x

Stokes, P. (2012, October 4). No, you're not entitled to your opinion. The conversation. https://theconversation.com/no-youre-not-entitled-to-your-opinion-9978

Journal of the Scholarship of Teaching and Learning, Vol. 21, No. 4, December 2021. josotl.indiana.edu 